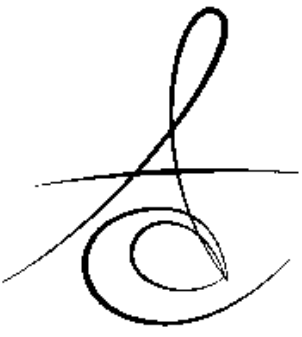

\title{
TRİKALSİYUM SİLİKAT İÇERİKLİ FARKLI ENDODONTİK MATERYALİN SEBEP OLDUĞU KORONAL DİŞ RENKLENMESİNİN SPEKTROFOTOMETRİK ANALIZZ YÖNTEMİ İLE DEĞERLENDİRİLMESİ
}

\section{IN VITRO SPECTROPHOTOMETRIC ANALYSIS OF CORONAL TOOTH DISCOLORATION INDUCED BY THREE DIFFERENT TRICALCIUM SILICATE BASED ENDODONTIC MATERIALS}

Arş. Gör. Funda YILMAZ*

Arş. Gör. Dt. Melis ALAV***

Makale Kodu/Article code: 3402

Makale Gönderilme tarihi: 02.03.2017

Kabul Tarihi: 02.02.2018

\section{öz}

Amaç: Bu çalışmada amaç trikalsiyum silikat içerikli materyallerin koronal diş renklenmesine etkisinin spektofotometre ile değerlendirilmesidir.

Gereç ve Yöntem: Bu çalışmada 50 adet maksiller santral diş kullanıldı. Dişler rastgele 5 gruba $(n=10)$ ayrıldı. Dişler $37{ }^{\circ} \mathrm{C}$ in \% 100 nemli ortamda bekletildi. Diş köklerinin apikal kısımları ， mine-sement birleşi minin $2 \mathrm{~mm}$ apikalinden elmas frezlerle uzaklaştırıldı . Ardından apikal giriş , Gates Glidden frezler 1 numaradan 6 kadar kullanılarak genişletildi. Gruplar; Negatif kontrol grubu, Biodentin, Bioaggregate, ProRoot MTA ve Pozitif kontrol grubu (defibrine koyun kanı) olarak belirlendi. Reperatif materyal $2 \mathrm{~mm}$ kalınlıkta olacak şekilde kaviteye yerleştirilip cam iyonomer siman ile kavite girişi kapatıldı. Renk ölçümünde Vita Easyshade Advance spektrofotometre kullanıldı . Materyaller yerleştirilmeden önce (T0), yerleştirildikten sonra 1 . Hafta (T1), 2. Hafta (T2), 1 ay (T3) ve 2 ay (T4) olmak üzere 5 defa ölçüm yapılarak renk değişim mik tarları $(\Delta \mathrm{E})$ değerlendirildi. Commission Internationale' de l'eclairage L*a*b* değişimleri her grup için ölçülerek karşılaştırıldı.

Bulgular: Negatif kontrol grubu, Biodentin ve Bioaggregate gruplarında, diş kronunda anlamlı derecede renk değişikliği görülmedi. Ayrıca bu gruplar ProRoot MTA ve Pozitif kontrol grubuna göre daha az renkleşmeye sebep oldular. Pozitif kontrol grubu ve ProRoot MTA gruplarında 2 aylık değerlendirme sürecinde $L^{*}$ değerlerinin düştüğü ve zaman ilerledikçe örneklerin renginin koyulaştığı gözlendi.

Sonuç: Estetiğin önem kazandığı ön grup dişlerde, MTA'ya alternatif olarak, trikalsiyum silikat içerikli Biodentine veya Bioaggregate gibi dentin tamir materyalleri tercih edilebilir.

Anahtar Kelimeler: Bioaggregate, Biodentin, ProRoot MTA, spektrofotometre

\section{ABSTRACT}

Aim: The aim of this study is to evaluate the coronal tooth discoloration caused by the materials used in such applications, by using spectrofotometre.

Material and Methods: Fifty extracted human maxillary central incisor teeth were used in this study. Teeth were randomly assigned into 5 groups $(n=10)$ and stored in saline solution at $37{ }^{\circ} \mathrm{C}$ in $100 \%$ humidity. Apical part of the root, was removed $2 \mathrm{~mm}$ below the semento-enamel junction. Then apical access cavity was made in 5 groups and prepared by using Gates Glidden files (Dentsply, Maillefer, USA) at number 1 to 6 . The groups were as follows: Negative control group, Biodentin, Bioaggregate, ProRoot MTA and Positive control group (bovine animal blood). A 2$\mathrm{mm}$-thick increment of reparative material was placed on the pulpal floor, covered by glass ionomer cement. Color change was evaluated with Easyshade Advance Spectrophotometer at 5 time points: day 0 (T0), day 7 (T1), day 14 (T2), 1 month (T3) and 2 months (T4). Changes in Commission Internationale de l'eclairage L*a*b* were measured for each experimental group and compared with each other.

Results: There were no significant differences between negative control group, biodentin and bioaggregate group. These groups produced significantly less discoloration than ProRoot MTA and positive control group. There were significant drops in the values of $L^{*}$ from T0 to T4 in the Positive control group and ProRoot MTA group. The values decreased over time as the samples became darker..

Conclusions: Tricalcium Silicate based materials such as Biodentine or Bioaggregate can be prefer instead of MTA in the anterior teeth, where the esthetic outcome is very important.

Keywords: Bioaggregate, Biodentin, ProRoot MTA, spectrophotometre

* Ankara Üniversitesi Diş Hekimliği Fakültesi, Endodonti AD, Ankara. 


\section{GİRİş}

Diş hekimliğinde estetiği sağlamak için, dişler restore edildikten sonra, dişeti, dudaklar ve yüz ile uyum içerisinde olması gerekmektedir. ${ }^{1}$ Son yıllarda, diş tedavisi gören hastaların, dişlerin estetik görünümüyle ilgili beklentisi oldukça artmıştır ve diş rengi estetik görünümü etkileyen en önemli faktörlerden birisidir. $^{2}$

Endodontik tedavi sırasında kullanılan irrigasyon solüsyonları, medikamanlar ve kanal dolgu maddleri koronal diş renkleşmelerine sebep olabilir. ${ }^{3}$ Ayrıca direkt pulpa kapaklaması, aşamalı çürük tedavisi, Cvek ampütasyonu, perforasyon tamiri ve rejeneratif endodonti gibi pulpa tedavi uygulamaları da dişin koronal üçlüsüne, renklenmeye sebep olabilecek materyaller yerleştirilmesini gerektirebilir.4,5 Endodontik materyallerin kullanımasının ardından oluşabilecek bu renkleşmeler, kullanılan materyallerin dentin tübüllerine penetrasyonuna veya kendi içerisinde renklenen materyalin, diş sert dokularından dışarıya yansımasına bağlı olarak meydana gelebilir ${ }^{6,7}$.

MTA, üstün tıkama kabiliyeti ve uzun vadede başarılı prognostik sonuçları olan, biyouyumlu bir tamir materyalidir. Endodontik tedavi esnasında önerilen kullanım alanları; kök perforasyonlarının ve internal kök resorpsiyonlarının onarımı, retrograt kök kanalı dolgusu gibi dentin tamir materyali olarak ayrıca, perforasyon tamiri, direk pulpa kapaklaması, apeksifikasyon ve pulpa revaskülarizasyon tedavilerinde de sıkIıkla kullanılmaktadır. Ancak diş kronunda renklenmeye

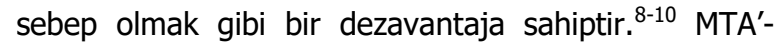
nın, diş kronunda sebep olduğu renkleşmeleri ortadan kaldırmak için, formülünde değişiklikler yapılmış ve beyaz MTA geliştirilmiştir. ${ }^{11}$ Bazı çalışmalarda, beyaz MTA'nın da diş kronunda renkleşmelere sebep olduğu bildirilmiştir. ${ }^{12}$

Son yıllarda kullanıma giren diğer biyoaktif trikalsiyum silikat simanların, koronal renkleşmeye sebep olmadıkları iddia edilmektedir. 2011 yılı başlarında, Biodentine (Septodont, Saint Maur des Fosses, France) yeni bir bioaktif siman ve 'dentin tamamlayıcı materyal' olarak, tek doz kapsül içerisinde, amalgamatörde 30 saniye karıştırarak kullanılmak üzere, toz ve likit olarak piyasaya sürülmüştür. Trikalsiyum silikat, kalsiyum karbonat ve zirkonyum oksit içeren, silikat bazlı bir endodontik tamir materyalidir. ${ }^{13,14}$ Biodentine (BD) reaksiyoner dentin ve dentin köprüleri oluşturarak, pulpa iyileşmesini ve remineralizasyonu uyaran triklsiyum silikat siman içerir. ${ }^{15}$ BioAggregate (Innovative Bioceramix, Vancouver, BC, Canada), seramik içerikli bir tamir materyalidir. Beyaz kristalsi toz içinde kalsiyum silikat, hidroksiapatit, kalsiyum fosfat, amorf silikon oksit, kalsiyum hidroksit ve tantal oksit vardır. Deiyonize su ile karıştırılarak kullanıır. ${ }^{16}$

Son yıllarda yapılan in vitro ve in vivo çalışmalar, Biodentine ve Bioaggregate'in tıkama yeteneği ve biyouyumluluğunun MTA ile karşılaştırılabilir olduğunu göstermektedir. ${ }^{17-20}$ Ancak iki materyalin diş rengi üzerine etkisi tam olarak bilinmemektedir. $\mathrm{Bu}$ in vitro çalışmanın amacı, trikalsiyum silikat içeren MTA, Biodentine ve Bioaggragate gibi endodontik materyallerin sebep olduğu koronal diş renkleşmesinin spektrofotometrik analiz yöntemi ile değerlendirilmesidir.

\section{GEREÇ VE YÖNTEM}

\section{Örneklerin Hazırlanması}

Ankara Üniversitesi Etik Kurulu tarafından onaylanan çalışmamızda, periodontal nedenlerle, benzer yaş grubundaki hastalardan yeni çekilmiş, üzerinde restoratif işlem olmayan, çürüksüz, benzer çap ve boyutlarda 50 adet maksiller santral diş kullanıldı. Dişlerin üzerindeki eklentiler ve yumuşak doku artıkları periodontal küret yardımıyla temizlendi. Diş köklerinin apikal kısımları, mine-sement birleşiminin $2 \mathrm{~mm}$ altından, su soğutmalı aeratöre takılan elmas frezlerle (ISO 806314, 014, Meisinger, Germany) uzaklaştırıldı. Dişlerin koronal kısmındaki pulpa dokusu tirnerfler kullanılarak, apikal girişten çıkarıldı. Apikal giriş 1, 2, 3, 4, 5, 6 numaralı Gates Glidden frezler (Dentsply, Maillefer, USA) ile 1'den 6'ya kullanılarak genişletildi. Apikal giriş kavitesi $3 \mathrm{~mm}$ çap ve $3 \mathrm{~mm}$ derinliğe sahip olacak şekilde oluşturuldu. Derinlik ve çap ölçülmesinde periodontal sond kullanıldı. Ayrıca örnek dişlerin bukkal duvar kalınlığı $2 \mathrm{~mm}$ olacak şekilde elektonik kaliper ile ölçüldü. Gates-Glidden frezlerin her değişiminde $2 \mathrm{ml} \% 5$ 'lik sodyum hipoklorit (Wizard, Rehber Kimya, Türkiye) ile yıkama yapıldı. Smear tabakasının uzaklaştırılması amacıyla, 5ml \%17'lik EDTA (Werax, Spotdent, Türkiye) hazırlanan apikal giriş kavitesine uygulandı ve 1 dakika süreyle bekletildi. EDTA'nın ardından, tekrar $2 \mathrm{ml} \% 5^{\prime}$ lik $\mathrm{NaOCl}$ ile yıkama işlemi uygulandı ve son olarak her diş $2 \mathrm{ml}$ serum fizyolojik ile yıkandı. Örnekler, her birinde 10 adet diş olacak şekilde, 3 deney grubu, 1 pozitif kontrol grubu ve 1 
negatif kontrol gurubu olmak üzere, rastgele 5 gruba ayrıldı ve her dişe bir numara verildi.

Deney gruplarl; 1. Grup: Negatif kontrol grubu, 2. Grup: Biodentine, 3. Grup: Bioaggregate, 4. Grup: ProRoot MTA ve 5. Grup: Pozitif kontrol gurubu olarak belirlendi. Negatif kontrol grubunda, dişler $2 \mathrm{ml}$ serum fizyolojik ile yıkandı, herhangi bir materyal uygulanmadı. Biodentine (Septodont, Niederkasssel), BioAggragate (Innovative BioCeramix, Vancouver, Canada) ve ProRoot MTA (Dentsply Maillefer, Ballaigues, İşviçre), üretici firmalarının önerisi doğrultusunda hazırlandı ve kağıt konlarla kurulanan apikal giriş kavitelerine $2 \mathrm{~mm}$ kalınlıkta olacak miktarda uygulandı. Pozitif kontrol grubu için, $0,2 \mathrm{ml}$ defibrine koyun kanı dental enjektörle her dişin apikal giriş kavitesine uygulandı. Materyallerin giriş kavitelerine uygulanmasının ardından, apikal giriş kaviteleri cam iyonomer siman ile kapatılı.

Deneyde kullanılan dişler, içleri yarıya kadar distile su ile dolu Eppendorf tüpleri içerisine, kronları suyun içerisinde kalacak şekilde, numaralarına göre yerleştirildi ve ağız ortamını taklit etmesi amacıyla deney süresi boyunca tüpler $37^{\circ} \mathrm{C}^{\prime} \mathrm{de}$ inkübatörde bekletildi.

\section{Renk Analizi}

Renk değişikliği ölçümleri, test materyalinin yerleştirilmesinden önce (T0), 1 . hafta $(\mathrm{T} 1), 2$. hafta (T2), 1. ay (T3) ve 2. ay (T4) olmak üzere 5 kez tekrarlandı. Dişlerin renk ölçümlerini yapmak için spektrofotometre (Vita Easyshade Advance, Zahnfabrik H. Rauter GmbH \& Co. KG, Germany) kullanıldı. Her ölçümden önce spektrofotometre üretici firmanın önerisi doğrultusunda kalibre edildi. Renk ölçümü minesement birleşiminin $3 \mathrm{~mm}$ yukarısından, dişin orta noktasından yapıldı. Her örnek 3 kez ölçüldü, ortalama değer alındı ve $L^{*}, a^{*}$ ve $b^{*}$ değerleri elde edildi.

$L^{*}$ değeri açıkığı temsil eder. Siyah rengin $L^{*}$ değeri 0 , beyaz rengin $L^{*}$ değeri 100 olarak kabul edilir. $L^{*}$ değeri büyüdüğünde objenin rengi açılmaktadır. Örneklerdeki renk değişiklikleri şu formüle göre ölçüldü: $\Delta \mathrm{E}=\left(\left(\Delta \mathrm{L}^{*}\right)^{2}+\left(\Delta \mathrm{a}^{*}\right)^{2}+\left(\Delta \mathrm{b}^{*}\right)^{2}\right)^{1 / 2} . \Delta \mathrm{E}$ değeri iki obje arasındaki renk değişikliğinin toplam büyüklüğünü temsil eder. $\Delta \mathrm{E}$ arttıkça, objenin rengi koyulaşmaktadır.

\section{İSTATİSTİKSEL ANALİZ}

Bu çalışmada elde edilen veriler SPSS 20 paket programı ile analiz edilmiştir. Trikalsiyum silikat grupları ve ölçüm zamanları arası farklılıklar incelenirken değerler normal dağıması nedeniyle, Tekrarlı Ölçümler İki Yönlü Varyans Analizi Testi kullanıımışır. Sonuçlar yorumlanırken anlamlılık düzeyi olarak 0,05 kullanılmış olup $p<0,05$ olması durumunda farkllığı olduğu; $p>0,05$ olması durumunda ise anlamlı bir farkllığın olmadığı belirtilmiştir.

\section{BULGULAR}

Trikalsiyum silikat içeren farklı kök kanal tamir materyallerinin, farklı zaman periyotlarında dişler üzerinde oluşturduğu renklenmelerin $(\Delta \mathrm{E})$ ortalama değerleri Tablo 1'de gösterilmiştir. Deney gruplar arasında ölçüm zamanları arasında istatistiksel olarak anlamlı bir farklılık görülmediği saptandı $(p<0,05)$. 1 . ve 2. haftalarda ölçülen renk değişim miktarları $(\Delta \mathrm{E}) 1$. ay $(0,000)$ ve 2 . ayda $(0,003)$ ölçülen renk değişim miktarlarından $(\Delta \mathrm{E})$ anlamlı olarak daha düşüktür Çalışmamızda kullanılan materyallerin, diş kronunda meydana getirdiği renkleşme miktarlarında $(\Delta \mathrm{E})$ da istatistiksel olarak anlamlı farklılıklar görülmüştür. Pozitif kontrol grubunda ölçülen değerler, Biodentine $(0,005)$, Bioagreegate $(0,000)$ ve negatif kontrol gruplarında ölçülen değerlerden anlamlı olarak daha yüksektir (Şekil 1).

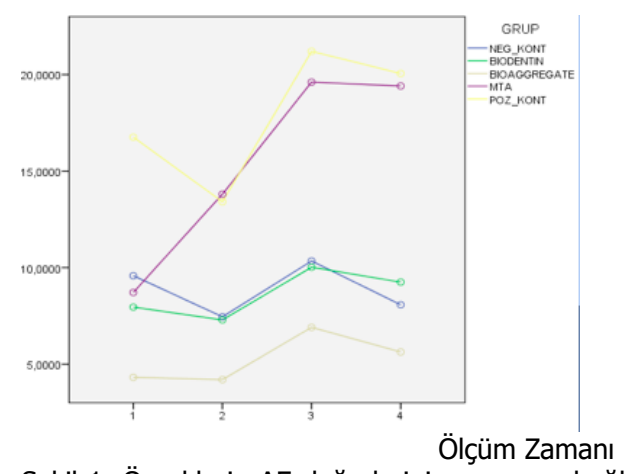

Şekil 1. Örneklerin $\Delta \mathrm{E}$ değerlerinin zamana bağlı değişiminin karşılaştırılması

Örneklerden ilk ölçümde (T0) elde edilen açıklık değerleri $\left(L^{*}\right)$, diğer tüm zamanlarda ölçülen $L^{*}$ değerlerinden anlamlı olarak daha yüksektir $(p=0,000)$. Aynı zamanda 1 . hafta ve 2 . hafta ölçülen $L^{*}$ değerleri, 1.a y $(0,000)$ ve 2 . ay $(0,000)$ ölçülen $L^{*}$ değerlerinden anlamlı olarak yüksektir. Pozitif kontrol grubundan elde edilen $L^{*}$ değerleri, trikalsiyum silikat içerikli diğer deney materyallerinden elde edilen $L^{*}$ değerlerinden anlamlı olarak daha düşüktür (Şekil 2). Biodentin ve bioaggregat grupları arasında istatistiksel olarak an- 
lamlı bir fark bulunmamışır; ancak MTA gurubunun L değerlerinin, Bioggregate grubunun $L$ değerlerinden istatistiksel olarak anlamlı derecede daha düşük olduğu görülmektedir.

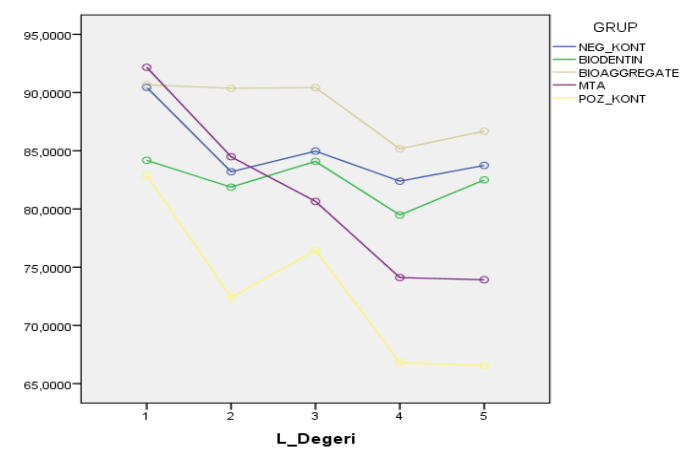

Şekil 2. Örneklerin $L$ değerlerinin zamana bağlı değişiminin karşılaştıııması

Tablo 1. Örneklerin farklı zaman periyotlarında dişler üzerinde oluşturduğu renkleşmelerin $(\Delta \mathrm{E})$ ortalama değerlerinin karşılaştırılması.

\begin{tabular}{|l|l|c|c|c|}
\hline & GRUP & Mean & $\begin{array}{c}\text { Std. } \\
\text { Deviation }\end{array}$ & N \\
\hline \multirow{5}{*}{ 1. hafta (T1) } & NEG_KONT & 9,58 & 3,38 & 10 \\
& BIODENTINE & 7,95 & 5,95 & 10 \\
& BIOAGGREGATE & 4,31 & 1,70 & 10 \\
& MTA & 8,71 & 4,73 & 10 \\
& POZ_KONT & 16,75 & 10,83 & 10 \\
\hline & Total & 9,46 & 7,18 & 50 \\
\hline \multirow{5}{*}{ 2. hafta (T2) } & NEGG_KONT & 7,45 & 4,02 & 10 \\
& BIODENTINE & 7,28 & 8,81 & 10 \\
& BIOAGGREGATE & 4,19 & 1,69 & 10 \\
& MTA & 13,80 & 8,96 & 10 \\
& POZ_KONT & 13,41 & 8,03 & 10 \\
\hline & Total & 9,23 & 7,67 & 50 \\
\hline \multirow{5}{*}{ 1. ay (T3) } & NEG_KONT & 10,34 & 4,66 & 10 \\
& BIODENTINE & 10,02 & 5,79 & 10 \\
& BIOAGGREGATE & 6,90 & 2,74 & 10 \\
& MTA & 19,60 & 6,77 & 10 \\
& POZ_KONT & 21,20 & 10,20 & 10 \\
\hline & Total & 13,61 & 8,49 & 50 \\
\hline \multirow{5}{*}{ 2. ay (T4) } & NEG_KONT & 8,07 & 3,80 & 10 \\
& BIODENTINE & 9,24 & 6,97 & 10 \\
& BIOAGGREGATE & 5,62 & 1,99 & 10 \\
& MTA & 19,40 & 6,02 & 10 \\
& MOZ_KONT & 20,05 & 7,90 & 10 \\
\hline & POZ_KONT & 12,48 & 8,22 & 50 \\
\hline & Total & & &
\end{tabular}

\section{TARTIŞMA}

Endodontik tedavi sonrasında meydana gelen diş renklenmeleri, diş hekimliğinde ciddi estetik problemlere sebep olabilmektedir. ${ }^{7}$ Diş renklenmelerinin çeşitlerine bakıldığında, bu tip renklenmeler içsel renklenmeler grubunda yer alır ve nekrotik pulpa dokusu birikimi, pulpa boşluğuna hemoraji ve endodontik tedavi sırasında kullanılan materyallere bağı oluşabilmektedir. ${ }^{21}$ Endodontik tedavi sonrası kronda meydana gelen renkleşmelerin, ilaç ve kök kanal dolgu materyallerinin doğru seçilmesiyle azaltılabileceği bildirilmiştir. ${ }^{22}$ Doğru materyali seçebilmek için, kullanılan materyallerin renklendirme potansiyelleri ile ilgili doğru bilgilere sahip olmak gerekir; ancak literatürde dişleri boyayan materyaller konusundaki bilgiler oldukça sınırlıdır. ${ }^{7}$ Bu nedenle çalışmamızda MTA, Biodentin, BioAggregate simanlarının renkleşme potansiyelleri karşılaştırıldı.

Çalışmamızda kullanılan simanların zamana bağlı renkleşme miktarlarını analiz edebilmek için Vita Easyshade Compact kullanılmışır. Vita EasyShade Compact küçük değişiklikleri algılayabilen, tekrarlanabilen ölçümler yapılmasına olanak veren ve renk değişikliğini rakamlarla somut bir şekilde belirleyebilen bir spektrofotometre cihazıdır. ${ }^{23} \mathrm{CIE}$, ISO tarafindan tanıtılan, ışık, görme ve renk konularının evrensel standardizasyonudur. CIE L*a*b*, tüm algılanabilir renklerin, insan gözünün alglayabildiği renklere yaklaştığı, 3 boyutlu bir sistemdir. Rengin CIE L*a*b* sistemindeki yeri, 3 kromatik parametre kullanılarak belirlenir. $L^{*}$ değeri açıklığı temsil eder ( $L^{*}=0$ siyah, ve $L^{*}=100$ beyaz). a* ve $b^{*}$ değerleri sırasıyla, yeşilden $(-a)$ kırmızıya $(+a)$ ve maviden $(-b)$ sarıya $(+b)$ eğilimi temsil eder. İki obje arasındaki renk değişikliğinin toplam büyüklüğü ise $\Delta \mathrm{E}=\left(\left(\Delta \mathrm{L}^{*}\right)^{2}+\left(\Delta \mathrm{a}^{*}\right)^{2}+\right.$ $\left.\left(\Delta b^{*}\right)^{2}\right)^{1 / 2}$ formülü kullanılarak elde edilen $\Delta \mathrm{E}$ değerleriyle rakamsal olarak açıklanabilir. ${ }^{24}$

MTA, portland çimentosunun modifiye bir formudur. MTA'nın ağırlıkça \%75'ini portland çimentosu oluşturur. İçeriğinde portland çimentosundan farklı olarak bizmut oksit bulunur ${ }^{25,26}$. Yapılan in vitro ve ex vivo çalışmalar, beyaz MTA'nın da koronal diş renklenmelerine sebep olabileceğini göstermişlerdir. ${ }^{27,24,9,28}$ Renkleşmeye sebep olan demir $\left(\mathrm{Fe}_{2} \mathrm{O}_{3}\right)$, bizmut $\left(\mathrm{Bi}_{2} \mathrm{O}_{3}\right)$, alüminyum $\left(\mathrm{Al}_{2} \mathrm{O}_{3}\right.$ ) ve magnezyum (MgO) gibi çeşitli metal oksitler, Gri MTA içerisinden çıkartılarak MTA'nın formülü yenilenmiş ve beyaz MTA olarak üretilmiştir. ${ }^{11}$ Çalışmamızda en fazla renk değişikliği, $\Delta \mathrm{E}$ değeri $T 1$ 'de 8.7'den, T4'de 19.4'e yükselen ProRoot MTA grubunda görülmüştür. Bu sonuçlar beyaz MTA'nın zaman içerisinde diş yapısını renklendirebileceğini ve estetik bölgede dikkatli kullanılması gerektiğini bildiren çalışmaları doğrulamaktadır. Felman ve Parashos ${ }^{29}$,

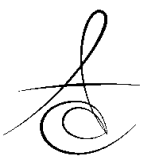


ortamda kan varlığı ve yokluğunda, MTA'nın diş kronunda sebep olduğu renkleşme miktarını değerlendirdikleri çalışmalarında, diş kronunda en fazla renkleşmenin kanın tek başına kullanıılığı pozitif kontrol grubunda gözlendiğini, ayrıca MTA'nın pulpa odasında kanama varlığında, yokluğuna göre daha fazla renkleşmeye sebep olduğunu bildirmişleridir. Bu renkleşmenin nedeni MTA tozundaki demir iyonunun oksidasyon mekanizmasıyla alakalı olabileceği gibi MTA'nın içeriğindeki ağır metal iyonları ve bizmut oksitin varlığı olabilir. Bizim çalışmamızda da, $L^{*}$ değerindeki en fazla düşüş, yani diş kronundaki en fazla renkleşme pozitif kontrol (koyun kanı) grubunda görülmüştür.

Biodentine, MTA'nın eksilerinin üstesinden gelmek için geliştirilmiş bir materyaldir. Biodentine içerisinde radyoopaklaştııı olarak, bizmut oksit yerine zirkonyum oksit kullanılmışı. ${ }^{13,} 30$ Marciano ve ark. ${ }^{30}$, Portland çimentosunu farklı radyoopasite sağlayıcılarla kullanmış, zirkonyum oksit ve kalsiyum tungstatın diş kronunun renginde bir değişiklik yapmadığını; ancak bizmut oksit kullanılan grubun kronunda renkleşme meydan geldiğini bildirmişlerdir. Valles ve ark. ${ }^{31}$, yaptıkları 5 günlük bir çalışmada, 5 farklı kalsiyum silikat bazlı materyali, oksijen ve anaerob ortama maruz bırakmış ve bizmut oksit içeren materyallerin koyulaştığını, Biodentine ve portland çimentosunun rengini koruduğunu gözlemlemişlerdir. Bizim çalışmamızda da bizmut oksit içeren beyaz MTA'nın, diş kronunu anlamlı derecede renklendirdiği gözlenirken, Biodentine grubunda istatistiksel olarak anlamlı bir fark gözlemlenmemiştir.

Bioaggregate içeriğinde radyoopaklaştıııı olarak MTA daki bizmut oksit yerine tantalyum oksit içerir. ${ }^{16}$ Literatürde, Bioaggregate'ın zaman içerisinde sebep olduğu renkleşmeyi, MTA ve Biodentine'in sebep olduğu renkleşmelerle karşılaştıran çok sayıda çalışmaya rastlanmamaktadır. Bu çalışmada, Bioaggreagate ile Biodentine'in diş kronunda benzer renk değişikliklerine sebep olduğu gözlemlenmiştir. Bu sonucun, iki materyalin de bizmut oksit içermemesine bağlı olduğu düşünülmektedir. Aynı zamanda çalışmamızda, 2. ayın sonunda, Bioaggregate'ın $L^{*}$ değerinin, 90,67'den, $86,68^{\prime}$ e, MTA'nın L* değerinin ise 92,17 'den 73,92 'ye düştüğü ve Bioaggragate'ın diş kronunda anlamlı olarak daha az koronal renkleşmeye sebep olduğu görülmüştür.

Yapılan bir çalışmada ise Bioaggreagate, Biodentine ve beyaz MTA klinik şartları temsil etmesi açısından kan varlığında oluşturdukları renkleşme değerlendirilmiştir. Bu çalışmada materyallerin oluşturduğu renkleşme 24 saat, 1 hafta, 1 ay, 3 ay ve 1 yilın sonunda izlenmiştir. İlk 24 saatin sonunda gruplar arasında anlamlı farklılık görülmemiş, bir ay sonra ise en fazla renk değişimi beyaz MTA grubunda gözlenirken 3 ay ve 1 yıllık takip sonrası en fazla renk değişimi sırasıyla koyun kanı, Bioaggregate, Beyaz MTA ve en az renkleşme Biodentine grubunda görülmüştür. ${ }^{32} \mathrm{Bu}$ durumu biodentinin daha hızı sertleşme süresiyle açıklamışlar ve kan komponetlerini daha hızlı bir şekilde bloke ettiğini öne sürmüşlerdir. Bioaggregate'in ise daha fazla sIvı çekme özelliğinden dolayı ortamdaki kanı absorbe ettiği böylece daha fazla renkleşmeye sebep olduğunu düşünülebilir. Bizim çalışmamıza benzer şekilde tek başına koyun kanı kullanılan grupta en fazla renk değişimi gözlenmiştir. Bu nedenle klinik uygulamalarda özellikle ön bölge dişlerinde çalışırken kanama kontrolünü sağlamak, estetik gereksinimler açısından ön planda tutulmalıdır.

Sonuç olarak, bu in vitro çalışmanın sınırlandırmaları doğrultusunda, estetik kaygıların olduğu bölgelerde, MTA'ya alternatif olarak, Biodentine ve Bioaggregate gibi bizmut oksit içermeyen materyallerin kullanılması tercih edilebilir. Eğer renkleşme sonucunda dişlerde beyazlatma işlemi yapmak gerekiyorsa, renkleşmenin hangi sebeple oluştuğu belirlenmelidir. Bunu bilmek beyazlatma sonrası dişin prognozunu belirlemek açııından da önemlidir. Ayrıca uzun dönemde beyazlatma tedavilerinden sonra eski rengine dönüş görülebilmektedir. ${ }^{33}$ Tüm bu olası durumlar göz önünde bulundurularak estetik ve fonksiyonel açıdan en uygun kritere sahip olan materyalin belirlenmesi gerekmektedir. Bu konuda daha fazla araştırma yapılmasına ihtiyaç vardır.

Funda Yılmaz: ORCID ID: 0000-0003-0815-5907

Aylin Kalaycıoğlu: ORCID ID: 0000-0002-

Melis Alav: ORCID ID: 0000-0001-5166-311X

\section{KAYNAKLAR}

1. Joiner A. Tooth colour: a review of the literature. J Dent 2004;32:1-12.

2. Watts A, Addy M. Tooth discoloration and staining: a rewiev of the literature. Br Dent J 2001;190:30916.

3. Ahmed HMA, Abbott PV. Discoloration potential of endodontic procedures and materials: a review. Int Endod J 2012; 45:883-7. 
4. Kahler B, Mistry S, Moule A, Ringsmuth AK, Case P, Thomson A, Holcombe T. Revascularization outcomes: a prospective analysis of 16 consecutive cases. J Endod 2014;40:333-8.

5. Karabucak B, Li D, Lim J, Iqbal M. Vital pulp therapy with mineral trioxide aggregate. Dent Traumatol 2005;21:240-3.

6. Davis MC, Walton RE, Rivera EM. Sealer distribution in coronal dentin. J Endod 2002; 28: 464-6.

7. Van der Burgt T, Mullaney T, Plasschaert A. Tooth discoloration induced by endodontic sealers. Oral Surg Oral Med Oral Pathol 1986;61:84-9.

8. Boutsioukis C, Noula G, Lambrianidis T. Ex vivo study of the efficiency of two techniques for the removal of mineral trioxide aggregate used as a root canal filling material. J Endod 2008;34:123942.

9. Parirokh $M$, Torabinejad $M$. Mineral trioxide aggregate: a comprehensive literature review--Part III: Clinical applications, drawbacks, and mechanism of action. J Endod 2010;36:400-3.

10. Üstün $Y$, Dinçer AN, Aslan T, Sağsen B. bir komplike kron-kök kiriginin koruyucu restorasyonu: vaka raporu. Atatürk Üniv Diş Hek Fak Derg 2013; 23: 235-8.

11. Asgary S, Parirokh M, Eghbal MJ, ve Brink F. Chemical differences between white and gray mineral trioxide aggregate. J Endod 2005;31:1013.

12. Watts JD, Helt DM, Beeson TJ, Kırkpatrıck TC, Rutledge RE. Effects of $\mathrm{pH}$ and mixing agents on the temporal setting of tooth-colored and gray mineral trioxide aggregate. J Endod 2007;33:9703.

13. Asgary S, Shahabi S, Jafarzadeh T. The properties of a new endodontic material. J Endod 2008; 34 : 990-3.

14. Gomes-Filho JE, Rodrigues G, Watanabe S, Estrada Bernabe PF, Lodi CS, Gomes AC Faria MD, Domingos Dos Santos A. Evaluation of the tissue reaction to fast endodontic cement (CER) and Angelus MTA. J Endod 2009;35:1377-80.

15. Borkar SA, Ataide I. Biodentine pulpotomy several days after pulp exposure: four case reports. J Conserv Dent 2015;18:73-8.
16. Park JW, Hong SH, Kim, JH., LEE, SJ., SHIN, SJ. XRay diffraction analysis of white ProRoot MTA and Diadent BioAggregate. Oral Surg Oral Med Oral Pathol Oral Radiol Endod 2010;109:155-8.

17. Chen I, Karabucak B, Wang C, Wang HG, Koyama E, Kohli MR, Nah HD, Kim S. Healing after rootend microsurgery by using mineral trioxide aggregate and a new calcium silicate-based bioceramic materyal as root-end filling materials in dogs. J Endod 2015;41:389-99.

18. Luo Z, Kohli MR, Yu Q, Kim S, Qu T, He WX. Biodentine induces human dental pulp stem cell differentiation through mitogen-activated protein kinase and calcium-/calmodulin- dependent protein kinase II pathways. J Endod 2014;40:937-42.

19. Nair U, Ghattas S, Saber M, Natera M, Walker C, Pileggi R. A comparative evaluation of the sealing ability of 2 root-end filling materials: an in vitro leakage study using Enterococcus faecalis. Oral Surg Oral Med Oral Pathol Oral Radiol Endod 2011;112:e74-7.

20. Nowicka A, Lipski M, Parafiniuk M, Sporniak-Tutak K, Lichota D, Kosierkiewicz A, Kaczmarek W, Buczkowska-Radlinska J. Response of human dental pulp capped with biodentine and mineral trioxide aggregate. J Endod 2013;39:743-7.

21. Nicholls E. Endodontics. 3. ed.. 3, Bristol, John Wright and sons Itd: 1976 . p. 339-40.

22. Ingle GI, Beveridge BE. Endodontics, 2 ed. 2. Philadelphia; Lea and Febiger Publishers: 1976. p.736-40.

23. Khokhar Z, Razzoog M, Yaman P. Color stability of restorative resins. Quintessence Int 1991;22:7337.

24. Ioannidis K, Mistakidis I, Beltes P, Karagiannis V. Spectrophotometric analysis of coronal discolouration induced by grey and white MTA. Int Endod J 2013; 46: 137-44.

25. Dammaschke T, Gerth HU, Zuchner H, Schafer E. Chemical and physical surface and bulk material characterization of white ProRoot MTA and two Portland cements. Dental Materials 2005;21:731-8.

26. Rao A, Shenoy R. Mineral trioxide aggregate: a review. J Clin Pediatr Dent 2009;34:1-7.

27. Belobrov I, Parashos P. Treatment of tooth discoloration after the use of white mineral trioxide aggregate. J Endod 2011;37:1017-20. 
28. Kım JH, Kım, Y, Shın SJ, Park JW, Jung IY. Tooth discoloration of immature permanent incisor associated with triple antibiotic therapy: a case report. J Endod 2010;36:1086-91.

29. Felman D, Parashos P. Coronal tooth discoloration and white mineral trioxide aggregate. J Endod 2013;39:484-7.

30. Marciano MA, Costa RM, Camilleri J, Mondelli RF, Guimaraes BM, Duarte MA. Assessment of color stability of white mineral trioxide aggregate angelus and bismuth oxide in contact with tooth structure. J Endod 2014;40:1235-40.

31. Valles $M$, Mercade $M$, Duran-Sindreu $F$, Bourdelande $\mathrm{J}$, Roing $M$. Influence of light and oxygen on the color stability of five calcium silicate-based materials. J Endod 2013; 39:525-8.

32. Yoldaş SE, Bani M, Atabek D, Bodur H. Comparison of the Potential Discoloration Effect of Bioaggregate, Biodentine, and White Mineral Trioxide Aggregate on Bovine Teeth: In Vitro Research. J Endod 2016;42: 1815-8.

33. Krastl G, Allgayer N, Lenherr $P$, et al. Tooth discoloration induced by endodontic materials: a literature review. Dent Traumatol 2013;29:2-7.

\section{Yazışma Adresi}

Dr. Dt. Funda Yılmaz

Ankara Üniversitesi Diş Hekimliği Fakültesi, Endodonti AD, Ankara, TÜRKİYE

Tel: 05055930693

Email: dt.fndylmz@gmail.com 